\title{
André Carneiro: la ciencia ficción y los límites de la literatura
}

Luciana Martine $^{1}$

\section{El género según Carneiro}

A mediados del siglo $X X$ algo inusitado comenzaba a despuntar en la literatura brasileña. Apenas una década antes del "tropicalismo", que acaso sea la marca más original de la vida e historia musical de Brasil, en la literatura comenzaba a gestarse una vertiente de la ciencia ficción que, en su diversidad, se concibió a sí misma como reivindicadora del valor absoluto de lo nuevo. ${ }^{2}$ Esta propuesta se presentaba como una respuesta a que, hasta la década del 50, toda la producción literaria que se orientara en Brasil hacia la ficcionalización de los problemas de la ciencia se encontraba con dos problemas. Por un lado, no existía en su realidad local inmediata (como, por el contrario, sucedió en EEUU) un contexto científico tecnológico que alimentara la usina de ideas literarias, razón por la cual la ciencia ficción en Brasil encontró su motor en otras literaturas traducidas, principalmente en la traducción de las obras de Julio Verne y H. G. Wells y, posteriormente, en las de figuras clásicas del género como Asimov, Bradbury, Heinlein, entre otros (Silva, 2011; Pereira, 2005). Sirve para pensar el caso brasileño el diagnóstico que Pablo Capanna, actor central de la ciencia ficción en Argentina (y con quien Carneiro compartiera en reiteradas ocasiones espacios de publicación en las revistas rioplatenses del género), hiciera en su momento sobre las narrativas locales:

Quizá el rasgo más común sea que nuestros escritores no hacen cf [ciencia ficción] a partir de ciencia, como ocurre en los países industrializados en donde la ciencia es una actividad socialmente prestigiosa y la tecnología impregna la vida diaria; son escritores que se han formado leyendo cf y en cuyo mundo espiritual importan las convenciones y los mitos del género. Decir que aquí se hace cf a partir de la cf no es decir que se hace literatura de segunda mano; por

\footnotetext{
${ }^{1}$ Doctora en humanidades y artes (mención en literatura) y docente de la Universidad Nacional de Rosario, Rosario, Argentina. (Dorcid.org/0000-0003-2625-0289. E-mail: luciananmartinez@gmail.com

2 Para ampliar, ver o "Manifesto Antropofágico da Ficção Científica Brasileira - Movimento Supernova" (Pereira, 2005, p. 145).
} 
el contrario puede significar cortar camino hacia las corrientes más avanzadas de ámbito mundial (Capanna, 1985, p. 56).

Por otro lado, excluyendo contadas excepciones como el caso de Machado de Assis, existía en Brasil una carencia de tradición vernácula de autores que hubieran incursionado en formas protogenéricas de la ciencia ficción; ${ }^{3}$ aspecto al que se sumó la particularidad de que nunca surgiera en el escenario brasileño (como en efecto sí sucedió en Estados Unidos y más tarde, en la década del 60, en el Reino Unido) una figura aglutinante que oficiara de cabeza editora o delimitara criterios estéticos de grupo o movimiento:

There was no cohesive science fiction tradition in Spanish and Portuguese-speaking world, and no Gernsback or Campbell to nurture writers and give the emerging genre a distinct shape and feel (Bell y Molina-Gavillán, 2003, p. 4).

En ese contexto surge, sin embargo (y contra todo pronóstico), hacia fines de la década del 50, el primer corpus coherente de ficción científica brasileña (Causo, 2003, p. 289), agrupado en las primeras antologías editadas por las editoriales GRD y Edart. Se trató de un grupo que surgió en la ola del boom editorial nacional y que rápidamente se encontró envuelto por un espíritu optimista que impregnaba la nación entera y sus expectativas de desarrollo, como contrapunto de las fantasías paranoides y de destrucción que fueron propias de la Guerra Fría y que alimentaban los imaginarios de la ciencia ficción en los países anglófonos. De alguna forma, esta denominada "generación GRD" o "Primeira onda" de la ciencia ficción se conformó mezclando ambos imaginarios o sensibilidades: la percepción optimista sobre el desarrollo brasileño y las escrituras distópicas que comenzaban a caracterizar al género en EEUU y cuyas traducciones llegaban a Brasil. En esa mezcla singular tal vez haya radicado (como se enuncia en el Manifiesto Antropofágico del género) el valor de su novedad absoluta; novedad que atrajo la atención de la comunidad académica internacional.

\footnotetext{
${ }^{3}$ Muchos de los relatos de Machado de Assis ("O alienista", 1882; "Conto Alexandrino", 1884; entre otros) muestran un claro interés por los tópicos de la ciencia, fundamentalmente la psiquiatría y la psicología. Su atención a las llamadas ciencias de la mente y su preocupación por orientar sus especulaciones literarias hacia formulaciones ontológicas de lo humano lo ubica como antecedente de Carneiro (y, en general, de la corriente del género a la cual el autor paulista pertenece).
} 
Sorteando los estigmas que han recaído históricamente sobre el género desde el punto de vista académico, es elocuente en este sentido que hacia 1976 se haya realizado bajo la pluma del por aquel entonces estudiante de postgrado David Dunbar la primera tesis de doctorado sobre la ciencia ficción brasileña (Dunbar, 1976). Dunbar había realizado durante la década del 70 una extensa investigación de campo en Brasil, momento en el que tuvo oportunidad de entrevistar a André Carneiro, autor que su director de tesis, Leo Barrow, había traducido con motivo de su publicación en una antología del género realizada en EEUU. Por eso, la mención a Carneiro resulta ya en esta instancia una referencia obligada.

Dentro de la "generación GRD", el paulista André Carneiro ocupó un lugar especial; no sólo por haber captado a partir de la década del 60 la atención de críticos y escritores de ciencia ficción a nivel internacional y haber sido publicado en diversas antologías junto con figuras de consagración, sino por su constante producción ficcional y crítica dentro del género. Si una figura como Pablo Capanna tiene en Argentina el mérito de haber escrito la primera historia de la ciencia ficción en español (El sentido de la ciencia ficción, 1967), a André Carneiro debe adjudicársele, simultáneamente, la primera reflexión de largo aliento sobre el tema en lengua lusófona.

En Introdução ao estudo da "science-fiction" (Carneiro, 1967), las comillas que el autor elige ponerle al nombre que se le asigna al género no responden solamente al hecho de que se lo enuncia en inglés: al igual que Pablo Capanna en su estudio, Carneiro detalla a lo largo de toda la primera parte de su Introdução... por qué considera que el género no ha encontrado una designación apropiada que pueda englobar todas sus manifestaciones. ${ }^{4}$ No obstante, luego de un recorrido pormenorizado por todas las definiciones acuñadas, Carneiro $(1967$, p. 12) se detiene en la reflexión del crítico paulista Otto María Carpeaux, en la que al parecer halla algo interesante: "Science-fiction" es un sustantivo compuesto y, como tal, implica que en la relación de asociación que es inherente a éste ninguno de sus términos guarda inalterada su acepción, en tanto los dos

\footnotetext{
${ }^{4}$ En el espacio de las revistas argentinas de ciencia ficción (en las cuales Carneiro publicó varios relatos) se realizan reflexiones similares en torno a la imposibilidad de encontrar un concepto unívoco que agrupe las textualidades de la "ciencia ficción". Este problema surge si se quiere incluir las heterodoxas ficciones locales que, sin ajustarse al modelo de la ciencia ficción clásica estadounidense, se encuentran cruzadas por problemas gnoseológicos propios de distintas disciplinas. Algo similar sucede, según se expresa en varios ensayos publicados en dichas revistas, si se revisa la "ciencia ficción" escrita en países europeos (Martinez, 2010a).
} 
sentidos se modifican recíprocamente. En este binomio, la "ciencia" no es simplemente teoría sino ficcionalización de la teoría; y la "ficción" deja de ser mera ficción para pasar a ser posibilidad científica, posibilidad ontológica de algo que a priori no es. Se trata de una ciencia que no busca comprobación sino aceptación en términos casi de fe, y de una ficción que (hoy diríamos) está más allá de cualquier proclama de autonomía y que, en cambio, juega a favor de la especulación ontológica.

Ahora bien, a partir del siglo XX comienzan a surgir nuevos problemas en la ciencia, nuevos paradigmas que se volverán dominantes dentro del campo epistemológico (Kuhn, 1962/2004), y que lógicamente afectarán el desenvolvimiento de la ficción que constituye el binomio de la "ciencia ficción". La reflexión de Carneiro (1967, p. 49) no es en absoluto ajena respecto de esto y de hecho le dedica un apartado de su Introdução... a "la ciencia del siglo XX". Refiriéndose a la mecánica cuántica (y también a la teoría de la relatividad a la que asimismo le dedica algunas referencias), Carneiro afirma que en la física actual la lógica del sentido común ya no existe, en la medida en que justamente un fenómeno puede ser tanto continuo como discontinuo. Este fenómeno, que en mecánica cuántica se conoce como "Principio de incertidumbre" (Heisenberg, 1955/1985), describe que a nivel subatómico la materia se comporta de forma diferente, como onda o como partícula, dependiendo de si interviene o no un observador; hecho que no sólo entra en expresa contradicción con las leyes de la física clásica materialista, sino con la percepción empírica. La nueva ciencia subatómica se rige así por leyes que dejan en jaque al sentido común, lo cual tiene para Carneiro (1967, p. 50) algo de "inmensamente poético", ya que evidencia la confluencia profunda de todas las cosas en un Todo. Esta afirmación casi mística, que tendrá fuerte asidero dentro de la literatura, fue alimentada por otro principio de la mecánica cuántica: el "principio de entrelazamiento" según el cual toda modificación en una partícula a nivel subatómico repercute en otras con las que no tiene necesariamente contacto (Schrödinger, 1956/1984). De ahí que los textos de Carneiro refieran expresamente en sus títulos esta fascinación por la incerteza cuántica y las implicancias poéticamente místicas que la literatura infiere de sus principios: Virtual realidade, Exemplos do insondável, Quânticos da incerteza, Confissões do inexplicável. 
Aunque representan una arista importante, las inquietudes de este movimiento del que Carneiro funcionó como narrador y crítico destacado no se agotan meramente en la mecánica cuántica. Diría, más bien, que sus temas se complejizan en conjugación con otros paradigmas menos legitimados. La "Primeira onda" de la ciencia ficción brasileña, de forma similar al movimiento que se denominó New Wave y que se nucleó alrededor de la revista británica New Worlds durante la década del 60, tuvo como su marca distintiva una especulación y trazado de ontologías ficcionales basados en distintas disciplinas humanistas como la psicología, la sociología, antropología $\mathrm{y}$, fundamentalmente, la parapsicología.

Este hecho se hace patente cuando en su Introdução... Carneiro no sólo menciona (dedicándole un apartado) a la parapsicología como uno de los temas centrales de la ciencia ficción, sino que ilustra dicha vertiente temática a partir de varios de sus textos. Al margen de que la parapsicología fue, a partir de la década del 50, efectivamente un tema privilegiado para la ciencia ficción canónica de la Edad de Oro campbeliana, la mención a esta disciplina de dudoso reconocimiento dentro del campo epistemológico debe leerse además, en el caso de Carneiro, en relación con otros factores. Por un lado, los fenómenos que estudia la parapsicología, como la telepatía o la telequinesis, encontraron en las teorías de la mecánica cuántica un renovado marco explicativo; en segundo lugar, es necesario visualizar el hecho de que André Carneiro, además de un actor central para la ciencia ficción brasileña, es una insoslayable figura de importación de la parapsicología como disciplina en Brasil. De alguna forma, sus dos textos de divulgación científica sobre hipnosis, O mundo misterioso do hipnotismo (Carneiro, 1963a) y Manual de hipnose (Carneiro, 1978), anticipan tempranamente este interés al centrarse en los efectos parapsicológicos que desata la estimulación del inconsciente a través del trance hipnótico.

La referencia a la parapsicología resulta interesante, entonces, por diversos motivos. Por un lado, como anticipé, fuera del campo literario, la parapsicología se apropia con frecuencia de formulaciones de la cuántica que le sirven para legitimar sus teorías; de ahí que ambos intereses aparezcan, como veremos a continuación, conjugados en los textos de Carneiro. Pero, además, cabría pensar que hay detrás de esta remanida tradición de la ciencia ficción que es la ficcionalización de contenidos 
científicos o pseudocientíficos, en este caso, de la parapsicología, las teorías sobre hipnosis, e incluso la cuántica.

De alguna manera, cuando Carneiro hace en el apartado dedicado a la importancia de la ciencia ficción afirmaciones tales como: "Não é a técnica que representa o verdadeiro perigo para a civilização, é a inércia das estruturas" (1967, p. 116) o, previamente, "Não é fácil se desligar de conhecimentos sedimentados em séculos ou de um condicionamento às "verdades" ouvidas na infância [...], repetidas em livros, sermões, escolas" (1967, p. 55), le está asignando, primero subrepticia y luego explícitamente, una función al género que atenta contra cualquier afirmación de autonomía literaria. Lo que impulsa la ficcionalización de paradigmas (en este caso: modelos nuevos o alternos) que es propia de la ciencia ficción responde a un objetivo que la ubica necesariamente más allá de la autonomía literaria, sin caer en lo que hoy podría llamarse "postautonomía" (Ludmer, 2010): se trata de una literatura en la que el ejercicio ficcional funciona, como afirma Carneiro, en pro de liberar al hombre de convencionalismos erróneos, sacudir conceptos establecidos, imaginar cambios en la sociedad (1967, p. 119). La "ficción" del binomio "ciencia ficción" propone un espaciolaboratorio en donde se ensayan posibles ontologías, tanto deseadas como indeseables, nuevos realismos basados en otros paradigmas fundantes. Si las múltiples propuestas teóricas sobre el realismo (Auerbach, 1993; Watt, 1957; Abrams, 1975; entre otros) coinciden en que no existiría un solo modelo sino distintos tipos de realismos que se formularían a partir de diversos paradigmas epistemológicos (así, por ejemplo, el realismo inglés del siglo XVIII tendría como base al empirismo según Ian Watt), puede perfectamente entenderse entonces que la propuesta realista de Carneiro conjuga en su base epistemológica postulados de la física subatómica, la parapsicología y las teorías sobre hipnosis. En este contexto, la ciencia ficción se prefigura como una brújula imaginativa en un derrotero incierto, la ficción nos advierte, profilácticamente, ficcionalizando paradigmas de la ciencia, sobre rumbos errados y nos ayuda a adaptarnos a nuevas ontologías que va trazando el devenir humano. Una vez más, puede pensarse a partir de las palabras de Pablo Capanna esta función propia del género cuyo solo reconocimiento diluye, en este caso, cualquier ilusión de autonomía: 
la s-f es un intento hecho a nivel mitológico, es decir sólo parcialmente consciente de sí, por reflejar el impacto del medio tecnológico en el hombre y trazar de algún modo las cartas de esa TERRA INCOGNITA que es el futuro (Capanna, 1967, p. 15).

\section{Especulaciones literarias}

En función de pensar nuevas ontologías que se correspondan con los nuevos paradigmas, Carneiro traza en sus ficciones toda una serie de problemáticas en donde cruza principios de mecánica cuántica, fundamentos de la parapsicología y su interés por la práctica de la hipnosis. Uno de sus cuentos más tempranos, "O homem que hipnotizava" (Carneiro, 1963b), tal vez pueda considerarse como comienzo de esta serie temática.

El universo de este relato está marcado por las especulaciones de Carneiro en torno a la hipnosis, tal como las desarrolla en su texto de divulgación $O$ mundo misterioso do hipnotismo. Allí, Carneiro reconstruye el trayecto de las funciones de la hipnosis a lo largo de la historia: desde las primeras teorizaciones por parte de su precursor Mesmer, hasta su empleo en las primeras prácticas del psicoanálisis freudiano, llegando hasta sus usos hospitalarios y quirúrgicos antes del descubrimiento de la anestesia química. La hipnosis, dice Carneiro en su texto, tiene la virtud de ser una cura a través de la palabra (1963a, p. 3), medio por el cual los padecimientos físicos pueden ser sanados. Pero ésta, contrariamente a lo que podría llegar a creerse, no es una práctica exótica, sino que puede instalarse en la cotidianidad. La inducción hipnótica está presente en la vida diaria, en las palabras tiernas y arrullantes de una madre hacia su hijo que está enfermo, en el tono acogedor de un médico que reconforta a su paciente, en el arropamiento y el canto curador de una abuela. Se trata de prácticas sugestivas que estimulan un estado de trance que repercute en el bienestar del sujeto. Incluso, dice Carneiro (yendo más allá), en teoría existe la posibilidad de establecer una cura por medio de la autohipnosis. Sobre esa posibilidad, y sobre los alcances de la autohipnosis como forma de modificación vital, versa "O homem que hipnotizava".

Es a partir de la práctica de la autohipnosis que el protagonista de "O homem que hipnotizava" lleva al límite en la ficción la pregunta 
idealista sobre la entidad y alcance de la percepción. Como en Plan de evasión de Adolfo Bioy Casares, el relato de Carneiro especula sobre las posibilidades de crear una realidad diferente por medio de la alteración de los sentidos, en este último caso, valiéndose de la autohipnosis. El protagonista del cuento, médico de formación, se pregunta ya en el comienzo del relato cómo es posible transformar los viejos puntos de vista, percibir de manera diferente los acontecimientos (Carneiro, 1963b, p. 61). El objetivo, de lo que se trata, como teorizará más adelante, es de intentar salir del "Prefácio" (1963, p. 67), es decir, de esa forma de vida en la que el disfrute queda supeditado a la planificación y el sacrificio individual en pos de la eventual realización de un futuro ideal en el que se espera llegarán a cumplirse todos los deseos. Para salir de la vida como "Prefácio" (concepto que vuelve en varias ocasiones a lo largo de la obra de Carneiro) se necesita comenzar a ver las cosas de otra manera. Es mediante la autohipnosis que el protagonista se induce un estado de trance permanente que le permite ver belleza en su mujer (que en verdad es horrible), percibir bonita su casa y su barrio proletarios, disfrutar de su trabajo alienante, convertirse en un incorregible y alegre optimista. La vida se vuelve, a través de la modificación de la percepción, un tránsito absolutamente disfrutable, al menos hasta el desenlace.

De esta forma Carneiro juega socarronamente, en este relato temprano, con poner a prueba de forma límite las posibilidades teóricas de un realismo que se sustente en la sugestión hipnótica. Por supuesto, la naturaleza hiperbólica de la ficción siempre supera cualquier expectativa real, pero indudablemente implanta la pregunta crítica sobre los posibles alcances de cualquier ejercitación perceptiva de este estilo: ¿acaso no son prácticas de este tipo (inducciones a la relajación que acompañan retóricas que predican los beneficios de la aceptación y adaptabilidad feliz de los sujetos) de las que se valen ciertas corrientes actuales de la New Age dentro del andamiaje de producción capitalista? Si la vida se ha transformado en una cárcel para el sujeto, a través de la rutina del trabajo, la explotación, la reducción a la pobreza y la monogamia (forma cultural del patriarcado que se constituye como el sostén mismo del sistema), tal vez la única forma de libertad posible radique en la modificación perceptiva: en la afirmación de un sujeto que se agencia de esa triste realidad en el acto 
de verla distinta. ${ }^{5}$ Por eso, cuando la práctica de autohipnosis pierde total efectividad hacia el desenlace del texto (sus sentidos ya no pueden ser engañados), el protagonista prefiere permanecer confinado en el hospital psiquiátrico, espacio que representa un claro afuera del sistema de producción y una posibilidad, en la exclusión, de consagración a una vida de lectura e investigación.

La propuesta ontológica que construye la ciencia ficción de Carneiro debe leerse, en este sentido, como atravesada por un gesto esencialmente político de desestabilización de cualquier reproducción inconsciente y acrítica de convenciones sociales. La construcción de un realismo sustentado en ese sincretismo que reúne distintos paradigmas (hipnosis, cuántica, parapsicología) no se juega en el espacio aséptico de los laboratorios o de las ideas científicas; por el contrario, representa siempre una puesta en cuestionamiento a partir de la ficción de estructuras profundas con las cuales el sujeto no sólo tiene una relación de pertenencia, sino de reproducción.

En sintonía, otros dos cuentos del autor paulista, "O homem que adivinhava" (Carneiro, 1966) y "Porta Atrás da Testa" (Carneiro, 2007), proponen un modelo de realismo basado, en estos casos, en principios de la física subatómica. El protagonista de "O homem que adivinhava" comienza el relato con una afirmación sobre su propia naturaleza: insiste en que a lo largo de su vida ha tenido recuerdos de cosas que nunca han sucedido; aunque en realidad, como el desarrollo del relato demostrará, él no recuerda, sino que experimenta imágenes de hechos que sucederán. En este sentido, recuerdo y predicción, pasado y futuro, se encuentran unidos para el sujeto en una experiencia presente. Si como propone la mecánica cuántica, tan mentada por Carneiro a lo largo de sus ficciones, todo el universo se encontraría (por principio de entrelazamiento) conectado, entonces una explicación posible radicaría en que un ser dotado podría tener experiencia de acontecimientos futuros. De este concepto se desprende asimismo la noción de "sincronicidad" que Jung, Rhine, Amodou, y tantas otras figuras representantes de corrientes alternas del pensamiento citadas por los personajes de Carneiro (1966, p. 54), retoman y desarrollan. Esta es la primera hipótesis que es posible

\footnotetext{
${ }^{5}$ El cuestionamiento a la monogamia es un tema clásico que Carneiro explora a fondo en sus dos novelas: Piscina livre (1980) y Amorquía (1991)
} 
reconstruir a partir de las citas en el relato: predecir el futuro, percibiéndolo como recuerdo de algo nunca sucedido es, sin más, producto de una experiencia consciente de la sincronicidad (esto es que, contrariamente a lo que podemos inferir a partir de nuestra constatación empírica, todos los hechos sucederían simultáneamente y que no habría un orden cronológico o causal). Fernando, el protagonista de "O homem que adivinhava", especula sobre la naturaleza de sus habilidades indagando en este sentido, pero también, valiéndose de los mismos principios sobre los que investiga a lo largo del texto mismo, propone otras explicaciones:

Como prevenir o governador? Seria levado em consideração? Se via o futuro, teria, por isso, a oportunidade de modificá-lo? [...] Fora seu aviso de morrer, ou aquilo já estava "escrito"? Como via o que ainda não acontecera? Os que tramavam o crime entrevisto emitiam ondas desconhecidas que ele captava, sendo sua previsão apenas uma dedução mental, ou "veria" mesmo o futuro? (Carneiro, 1966, p. 56).

La visión del futuro en este caso ya no sería tal (o al menos se duda sobre ello), sino una captación telepática de los pensamientos de los criminales que llevarían a cabo el delito, lo cual terminaría por transformarse en una imagen mental sobre el hecho en la cabeza del protagonista. Pero ambos casos, tanto la hipótesis sobre la captación de la sincronicidad como la del fenómeno telepático, se encuentran habilitados por las teorías que los personajes recorren en relación con la cuántica y las interpretaciones libres que de ella hacen las diferentes corrientes de la parapsicología.

La especulación en torno a los fenómenos telepáticos vuelve a ocupar tiempo después, en un cuento mucho más reciente como "Porta Atrás da Testa", un lugar destacado. Allí, el protagonista masculino es, al igual que en varios de los relatos de Carneiro, un médico psicólogo o psicoanalista (Joachim) que experimenta con una paciente mujer (Renata) a partir de la inducción hipnótica. Que surja en esa instancia de la trama el tema de los vínculos telepáticos entre ambos no sorprende; e incluso refleja la recuperación ficcional por parte del autor de un viejo debate que excede la serie literaria: el mismo Freud en un texto tardío como "Psicoanálisis y telepatía" (1921/1992) es quien, en una etapa de su obra en la que cierto prestigio y aceptación del psicoanálisis le permitía finalmente despacharse sobre inquietudes de dudosa procedencia, se encarga de analizar con 
seriedad momentos de manifestación del inconsciente (como el estado onírico) en los que surgen para él evidencias de trasmisión telepática.

Pero a diferencia del texto de Freud, la literatura avanza sobre otros terrenos, más libremente, a partir de la especulación ficcional. La constatación telepática y su ensayo explicativo no se presentan como límites, sino que el protagonista procede un paso más en sus elucubraciones:

Centenas de coisas passavam pela cabeça de Joachim. Em toda a história da parapsicologia, eram raríssimos e às vezes duvidosos os fenômenos feitos sob encomenda. Havia um americano que anunciava pagar um milhão de dólares para quem provocasse um fato evidente e fiscalizado. [...] Joachim temia que, sem aviso, Renata não mais conseguisse seus milagres. Nada garantiria uma demonstração pública com sucesso. E mesmo que tivesse, Joachim sabia, a publicidade seria vulgar, indiscreta e anticientífica. [...] Era inevitável, ele buscava um meio de fazê-la adivinhar algo em que ambos pudessem lucrar (Carneiro, 2007, p. 513).

Carneiro se toma con evidente humor (aunque esto no inhabilita en absoluto la seriedad que tiene para él el estudio de la parapsicología) el descrédito que suele recaer sobre cualquier disciplina que se aboque a lo paranormal. Sus personajes con frecuencia se presentan, además, como figuras que utilizan sus habilidades para sacar (o intentar sacar) provecho de todo tipo. Son sujetos que juegan con el registro del embaucador, el farsante, el impostor, pero que no dejan de evidenciar por eso un factor que es para las teorías de la parapsicología un pilar: la razón por la cual no se toma en serio a la parapsicología radica en que los fenómenos que estudia son espontáneos, producto de las manifestaciones espontáneas del inconsciente (Carneiro, 1963a), y, por lo tanto, inconstatables desde el punto de vista científico. Es precisamente el carácter inasible de los fenómenos parapsicológicos lo que incentiva a los personajes de Carneiro a explorar constantemente sus límites y potencialidades. ¿Hasta dónde podrán llegar los poderes de mi mente?, ¿cómo funciona mi mente?, ¿podré hacer esto que me propongo?, ¿cómo es posible que pueda?, ¿cómo podría sacarle provecho a mis habilidades?: todas preguntas que se realizan los personajes y que derivan, en un texto como "Porta atrás da testa", en un proyecto para hacer saltar la banca de la lotería nacional. Si Joachim vislumbra que su plan puede volverse una realidad efectiva es porque "não podia esquecer a velha teoria quântica do observador influindo no resultado da experiencia" (Carneiro, 2007, p. 516), es decir, 
especula sobre las implicancias impensadas que podía llegar a tener el "Principio de incertidumbre" de Heisenberg.

Otra vez aquí, las ontologías que se trazan a partir de la física subatómica y sus interpretaciones libres desde la parapsicología se juegan para el sujeto en el límite de la subversión. Las nuevas ontologías subjetivas no sólo cuestionan modelos epistemológicos que se basan en divisiones materialistas clásicas (sujeto-objeto, pasado-futuro) sino que implican un empoderamiento del sujeto que éste pone (o intenta poner) al servicio, aunque ante todo siempre en su beneficio, de la destrucción de viejas estructuras sociales o culturales respecto de las que se siente irremediablemente subyugado. Tanto en "O homem que adivinhava" como en "Porta Atrás da Testa", los poderes desarrollados por los personajes se emplean, en este sentido, para tratar de sacar un provecho económico que los libere finalmente del yugo del trabajo asalariado. El principio de Heisenberg se convierte así en el motor de una imaginería que excede el (pretendido) espacio política y culturalmente estéril de la ciencia y se orienta para pensar otros derroteros. Todo modelo de ciencia, parece querer decirnos Carneiro, propone sus ontologías y éstas tienen en lo real claras implicancias. Ante un cambio de modelo epistemológico sería inaudito pensar que el sujeto mismo, y las estructuras sociales que lo contienen, no se modificaran. Los actos delictivos de los nuevos sujetos de Carneiro, con sus nuevas habilidades, tal vez signifiquen en la ficción el anhelo de un resquebrajamiento inicial de estructuras sociales que necesariamente deberían reformularse para adecuarse a nuevas ontologías subjetivas, que aún se mueven en las arenas inciertas de la indefinición.

Siguiendo con esta línea, el imaginario de la física cuántica es retomado asimismo en otro relato clásico de Carneiro: “A máquina de Hyerónimus" (Carneiro, 1997). El motor narrativo del texto es precisamente la especulación sobre los alcances de dicha máquina, un dispositivo creado a fines de la década del 40 por el ingeniero estadounidense Thomas Galen Hieronymus cuyo objetivo era almacenar la energía "elóptica", un tipo de energía que, de forma similar a las viejas teorías sobre el "éter" o sobre la energía "óldica", se pensaba que era emanada por todos los objetos de universo. Pero lo interesante del asunto no es tanto la teoría de Hieronymus (considerada desde las filas de la ciencia como mera charlatanería) sino que John W. Campbell, editor y figura central de la ciencia ficción estadounidense de la Edad de Oro, 
hiciera a partir de ella una apropiación aún más descabellada. Para el editor de Astounding Science Fiction, el funcionamiento de la máquina se inscribía en el campo de la psiónica, es decir, se podría a partir de ella experimentar y conducir poderes paranormales latentes en la psiquis humana. En este sentido, el artefacto, que podía ser reemplazado por un esquema de papel que reforzara la seguridad del sujeto para desatar su fuerza inconsciente, funcionaba como una mera mancia, más que como un mecanismo complejo. ${ }^{6}$

Ahora bien, en su relato, Carneiro retoma explícitamente la interpretación de Campbell, dejando así en evidencia que el gusto de la ciencia ficción brasileña se inclina (como sucede en el resto de Latinoamérica) por temas que se acercan más a la exploración de teorías alternas de la mente que a hipótesis más cercanas a la ciencia legitimada. Por eso el protagonista compara el funcionamiento de la máquina con los experimentos con magnetismos que antaño realizaba Mesmer (Carneiro, 1997, p. 41), padre del hipnotismo. Ambos se apoyan en concepciones del mundo similares, aunque los métodos y las explicaciones se hayan vuelto más sofisticados. En este caso, como sucede en gran parte de los relatos que recorrimos, la novedad viene dada por el hecho de que la parapsicología y la fenomenología paranormal son interpretadas desde el universo teórico de la cuántica: cuando el personaje que se encuentra en poder de la máquina explica su funcionamiento a partir de experimentos (si se mata un animal en cautiverio usando la máquina también mueren otros especímenes con los que éste no tiene contacto directo; y de ahí que sea útil para controlar plagas) apela al "principio de entrelazamiento" para justificar los resultados:

- A máquina de Hyerónimus funcionava à base de... - parou, tentando esclarecer - você sabe, duas partículas subatômicas que interagiram um dia podem responder instantaneamente aos movimentos uma da outra, milhares de anos mais tarde... porém...

\footnotetext{
${ }^{6}$ En su Manual de parapsicología, el autor uruguayo Mario Levrero (con quien Carneiro entabló correspondencia luego de que ambos compartieran el espacio de publicación en las revistas argentinas del género) define el concepto de "mancia" como un ejercicio o empleo de objetos (uso de cartas, runas, etc.) que le permite al sujeto ganar seguridad y distraer su actividad consciente, de modo que surjan libremente fuerzas inconscientes que son las que en verdad operan detrás de todo fenómeno conocido como "adivinatorio". En realidad, lo que sucede según Levrero en esas instancias es que el sujeto, en un estado de trance, capta telepáticamente información que no conoce de forma consciente (Martinez, 2010b).
} 
[...] a máquina seria uma tentativa para... influenciar à distância... seres humanos, ou... a transmissor de mensagens diretas... [...] transmisor de pensamentos, ou ordens (Carneiro, 1997, p. 41).

Esto que para el protagonista parece en principio una "piada parapsicológica" (1997, p. 40), que no puede afrontar sino con humor, termina tomando la fuerza de una constatación (o, al menos, de un imperativo por otorgar el beneficio de la duda). Luego de ser conectado a la máquina, el protagonista experimenta en la vida real que sus deseos más íntimos y oscuros se vuelven realidad: es ascendido tras la muerte de su jefe y, como consecuencia, su nivel de vida y estatus económico-social se ven renovados. Como sucede en muchos de los relatos de Carneiro, lo que comienza como un chiste, teñido de descrédito y escepticismo, se transforma en una esperanza de salvación económica y de bienestar a la que los personajes se aferrarán. Se trata de una confianza ciega que, a partir del "Principio de incertidumbre", recae sobre el poder del observador: si hay pruebas fehacientes de que la presencia del observador llega incluso a determinar la presentación de la materia, ¿por qué no entender también que la prepotencia de su deseo puede determinar el curso de la realidad en sentidos aún más complejos? Este razonamiento se expone en la cita misma: la máquina funciona, por principio de entrelazamiento, afectando colateralmente partículas a distancia, pero esta operación es (según se desprende del principio de incertidumbre) dirigida por un sujeto transmisor que vuelve realidad sus pensamientos inconscientes más profundos gracias a la conexión con la máquina.

Sin apelar a un recurso tan propio de la ciencia ficción como es el imaginario maquinista, la especulación sobre la relación entre fenómenos paranormales y el principio de incertidumbre aparece de forma patente y original en un texto con el que me interesa completar finalmente el análisis: "O inenarrável" (Carneiro, 2007). En el contexto de una cena de amigos (uno de ellos psicoanalista) se propone un "juego de la verdad" que se encuentra peligrosamente teñido por el consumo de cannabis y alcohol. Las reglas del juego complejizan, además, el asunto: por turnos, todos deben hablar en forma anónima protegiendo la identidad de sus voces con un distorsionador y ocultando su rostro. En ese contexto, un deseo aúna las confesiones iniciales: todos habían tenido deseos o impulsos parricidas de importancia; uno de ellos, no obstante, afirmaba haber pasado al acto, haber matado a su padre, patriarcal y abusivo, durante la adolescencia. Pero la confesión, sorpresiva y espontánea, enrarece aún más la atmósfera 
de la reunión por los matices que aporta: el asesino (o asesina) afirma haber matado a su padre telequinéticamente, con la mera fuerza de su pensamiento, después de haber atravesado una etapa de sostenido entrenamiento mental. Lo que sigue a la confesión es toda una serie de especulaciones sobre si lo narrado sería posible, un recuento de teorías alternas y de saberes populares que lo justificarían y, finalmente, fuertes disquisiciones sobre las implicancias que tendría el reconocimiento de un hecho de tales características en el sistema jurídico de una sociedad. Otra vez la inconstatabilidad aparece como un problema propio de estos fenómenos relatados; sus implicancias ontológicas y normativas a nivel de organización social pertenecen, por ende, al terreno de lo incierto.

Desde la mitad del relato hacia el final, la intriga se posa, primero, sobre la identidad del asesino anónimo; pero luego, sobre el proceso de enfermedad y finalmente muerte de Olga (una de las integrantes de la reunión inicial), y sobre la posibilidad de que alguno de los demás participantes hubiera tenido algo que ver con su desenlace. Durante ese proceso que ocupa la mitad del relato, una idea, confusa al principio, comienza a emerger con insistente frecuencia en los distintos discursos de los personajes: todos, de alguna manera, se sienten esclavos de un accionar que no dominan, como si fueran muñecos, marionetas a la orden de una voluntad mayor. El dilema se resuelve jugando con los límites de lo literario en el relato mismo:

Mendez ironizou:

- Você recebeu essa ordem?

- Sim, mas ele também recebe ordens...

Libie cortou:

- Ele não recebe ordem nenhuma, ele faz de nós uns bonecos sem a menor piedade...

- Não é tanto assim, Libbie. Ele também sofre, tenho certeza que matou a Olga...

- Eu matei a Olga, por ordem dele, interrompeu o Mendez.

Ferraz continuou:

- Ele decidiu, a responsabilidade é dele, a consciência da culpa...

- Mas esse desgraçado mata todos nós e vai achar que está tudo muito bem, vai dormir sossegado.

- Não vai não. Ele não se sente bem, preferiria outra coisa, mas não achou uma solução.

- Não achou. Porque ele misturou realidade com invenção, aquela história do pai ser agressivo era real, verdadeira... 
- Já sei o que aconteceu - gritou Libbie. - Ele fez toda aquela confusão final porque, inconscientemente, sentiu-se culpado de ter matado o pai, que, na verdade ele não matou.

- Libbie, não está confuso isso?

- Está absolutamente claro. Ele sempre sentiu a falta de um pai amoroso e nos encarregou de matar o nosso pai, que, simbolicamente, era o pai dele. Depois se arrependeu, começou a nos punir, nos mostrar sem nenhum caráter, e está agora fazendo o absurdo de se meter na história, espécie de desculpa.

- Desculpa?

- Sim, desculpa, ele se arrependeu de ter nos mandado matar o pai, pois o pai, na verdade era dele, ele descreveu o próprio pai nesta história.

- Seria isso?

- É, foi isso mesmo. Afinal, meu pai foi uma vítima da época, acho que sofria, era um fraco fingindo sempre, acabou com a sua vida. Eu me sinto melhor agora, reconhecendo isso. Vou colocar FIM (Carneiro, 2007, p. 207-208).

La importancia que a partir de la mecánica cuántica adquiere el observador aparece, leído desde la parapsicología, tempranamente como tema en el relato (el asesinato del padre por medios telequinéticos), pero sobre ese fenómeno se da luego una vuelta de tuerca. El texto expone que el lugar en donde mayor primacía adquiere el observador es en el espacio literario, en el cual se constituye, por excelencia, como artífice de universos enteros. ${ }^{7}$ Como si el principio de incertidumbre rigiera, más allá de su pertenencia científica, en los dominios de la ficción, todo toma forma gracias y solo bajo la presencia de un observador que escribe. Pero la palabra es aquí, no obstante, como propone Carneiro en sus manuales sobre hipnosis, ante todo herramienta de cura. La expiación de una culpa y completar un proceso de comprensión o asimilación de experiencias traumáticas son el resultado de una terapéutica de la palabra que se

\footnotetext{
${ }^{7}$ La idea de que el "Principio de Incertidumbre" pertenece al ámbito de la ficción es una afirmación que realiza también César Aira: "Habrán reconocido el principio de Heisenberg, según el cual el observador, o la observación misma, modifica las condiciones objetivas del hecho. Más aún: disuelve la posibilidad de que el hecho tenga condiciones objetivas, lo vuelve observación, transformación, singularidad absoluta. El arte no debió esperar al descubrimiento de las partículas subatómicas para ver actuar el principio de Heisenberg, porque era la condición original de su funcionamiento, como lo es del funcionamiento del lenguaje: las palabras son delegados nuestros en el mundo, en la naturaleza, y allí se ocupan de cambiar los contornos de las cosas, o de darles contorno. Más en general, podría decirse que el principio de Heisenberg es la condición primera del funcionamiento de la conciencia; pero no de la inimaginable conciencia en sí, sino hecha lenguaje" (1993, p. 57).
} 
habilita como escritura de la ficción. El sujeto que escribe da forma, una y otra vez, a su universo íntimo a partir de su intervención y ese ejercicio es altamente sanitario.

En ese sentido, debe entenderse también que para Carneiro la literatura traspasa el límite más allá de cualquier autonomía, en tanto opera bajo fines que exceden el mero ejercicio lúdico de la creación ficcional libre. Si la función de la ciencia ficción, como género, es para Carneiro la de esbozar nuevas ontologías que permitan desandar estructuras de pensamiento y saberes anquilosados, la del ejercicio escriturario en general parecería responder asimismo a un objetivo terapéutico subjetivo; en ambos casos, la literatura es llevada a un límite. Sea cual fuere la meta que predomine singularmente en cada relato, el objetivo se persigue creando un tipo de realismo en donde los fenómenos paranormales, la hipnosis y los presupuestos de la física subatómica rigen de forma ineludible. Se trata de un realismo que, como afirma el autor con frecuencia en sus ficciones, pone el acento en facetas de la realidad veladas durante la cotidianeidad, nos permite pasar del otro lado del "espejo de Alicia".

\section{Referências}

ABRAMS, Meyer Howard (1975). El espejo y la lámpara. Teoría romántica y tradición crítica. Traducción de Melitón Bustamante). Barcelona: Barral.

AIRA, César (1993). La genealogía del monstruo. Paradoxa, Rosario, n. 7, p. 55-71.

ALEMAN, Jorge (2016). Horizontes neoliberales en la subjetividad. Buenos Aires: Grama.

AUERBACH, Erich (1993). Mimesis: la representación de la realidad en la literatura occidental. México: Fondo de Cultura Económica.

BELL, Andrea; MOLINA-GAVILLÁN, Yolanda (2003). Cosmos latinos: an anthology of science fiction from Latin America and Spain. Middletown, CT: Wesleyan University Press.

CAPANNA, Pablo (1967). El sentido de la ciencia ficción. Buenos Aires: Columba.

CAPANNA, Pablo (1985). La ciencia-ficción y los argentinos. Minotauro, Buenos Aires, n. 10, p. 43-56.

CARNEIRO, André (1963a). O mundo misterioso do hipnotismo. São Paulo: Edart.

CARNEIRO, André (1963b). Diário da nave perdida. São Paulo: Edart 
CARNEIRO, André (1966). O homem que adivinhava. São Paulo: Edart.

CARNEIRO, André (1967). Introdução ao estudo da "science fiction". São Paulo: Conselho Estadual de Cultura.

CARNEIRO, André (1978). Manual de hipnose. São Paulo: Resenha Universitária.

CARNEIRO, André (1997). A máquina de Hyerónimus e outras histórias. São Carlos: Editora da UFSCar.

CARNEIRO, André (2007). Confissões do inexplicável. São Paulo: Devir.

CAUSO, Roberto de Souza (2003). Ficção científica, fantasia e horror no Brasil -1875 a 1950. Belo Horizonte: Editora da UFMG.

DUNBAR, David Lincoln (1976). Unique motifs in Brazilian science fiction. Tesis (Doctorado en Literatura) - University of Arizona, Tucson.

FERREIRA, Rachel Haywodd (2004). The emergence of Latin American science fiction: a global genre in the periphery. Tesis (Doctorado en Español y Portugués) -Yale University, New Haven, CT.

FREUD, Sigmund (1921/1992). Psicoanálisis y telepatía. In: FREUD, Sigmund. Obras completas. Buenos Aires: Amorrortu. Tomo XVIII.

GANDOLFO, Elvio (2007). Fantasía y ciencia ficción latinoamericana. El libro de los géneros. Buenos Aires: Norma.

HEISENBERG, Werner (1955/1985). La imagen de la naturaleza en la física actual. Barcelona: Orbis.

KUHN, Thomas (1962/2004). La estructura de las revoluciones científicas. Traducción de Carlos Solís Santos. México: Fondo de Cultura Económica.

LUDMER, Josefina (2010). Aquí América Latina: una especulación. Buenos Aires: Eterna Cadencia.

MARTINEZ, Luciana (2010a). Políticas de traducción y publicación de las revistas de ciencia ficción argentinas (1979-1987). Sendebar. Revista de la Facultad de Traducción e Interpretación, Granada, n. 21, p. 109-138.

MARTINEZ, Luciana (2010b). Mario Levrero: parapsicología, literatura y trance. In: GIORDANO, Alberto (Ed.). Cuadernos del Seminario 1. Los límites de la literatura. Rosario: UNR.

PEREIRA, Fabiana da Câmara Gonçalves (2005). Fantástica margem: o cânone e a ficção científica brasileira. Tesis (Maestría en Letras) - Pontifícia Universidade Católica do Rio de Janeiro, Rio de Janeiro.

ROBERTS, Adam (2005). The history of science fiction. New York: Palgrave Macmillan. 
SCHRÖDINGER, Erwin (1956/1984). Mente y materia. Barcelona: Tusquets.

SILVA, Germano César da (2011). Piscina livre de André Carneiro: entre ícones e metamorfoses. Tesis (Maestria em Letras) - Universidade Federal de Pernambuco, Recife.

WATT, Ian (1957). The rise of the novel. Berkeley; Los Angeles: University of California Press.

WEIL, Simone (2006/1966). Sobre la ciencia. Buenos Aires: El Cuenco del Plata.

Recebido em 5 de junho de 2017.

Aprovado em 18 de outubro de 2017.

\section{resumo/abstract/resumen}

\section{André Carneiro: a ficção científica e os limites da literatura}

Luciana Martinez

A obra de André Carneiro representa uma das bases fundamentais da "GRD geração", o primeiro movimento da fiç̧ão científica no Brasil. Tanto em sua ficção quanto em seus ensaios, Carneiro propõe uma ideia de gênero conforme a qual o exercício literário é levado a um limite, questionando as afirmações em torno da autonomia literária. Partindo de um corpus que inclui diferentes textos emblemáticos da sua narrativa, analisaremos como o autor propõe ontologias literárias que ele formula apelando à construção de uma base epistemológica que reúne conceitos próprios da prática da hipnose (que Carneiro recupera de seus textos de divulgação) ou pertencentes à parapsicologia e à mecânica quântica. Assim, a proposta final de Carneiro parece orientada a construir, sob a influência de um sincretismo epistemológico que reúne os mencionados paradigmas, um modelo singular de realismo.

Palavras-chave: André Carneiro, ficção científica, limites da literatura, autonomia literaria, hipnose, parapsicologia, mecânica quântica, realismo.

\section{André Carneiro: science fiction and the boundaries of the literature}

Luciana Martinez

The work of André Carneiro is one of the fundamental branches of "GRD Generation", the first Brazilian science fiction movement. Both in his fictions and essays, Carneiro proposes an idea on genre according to which the literary exercise is pushed to a limit, questioning the assertions about literary autonomy. 
Based on a corpus that includes different emblematic texts from his narrative, it is analyzed how the author proposes literary ontologies that he formulates by building an epistemological core that gathers concepts typical of hypnosis practices (taken from his divulgation texts) or belonging to Parapsychology and Quantum mechanics. In this regard, Carneiro's final proposal seems to be oriented towards building, under the influence of an epistemological syncretism that gathers the paradigms above, a singular realistic model.

Keywords: André Carneiro, science fiction, boundaries of literature, literary autonomy, hypnosis, parapsychology, quantum mechanics, realism.

\section{André Carneiro: la ciencia ficción y los límites de la literatura}

\section{Luciana Martinez}

La obra de André Carneiro es una de las aristas medulares de la "Generación GRD", primer movimiento de la ciencia ficción en Brasil. Tanto en sus ficciones como en sus ensayos, Carneiro propone una idea sobre el género según la cual el ejercicio literario es llevado a un límite, poniendo en cuestión afirmaciones sobre la autonomía literaria. Partiendo de un corpus que abarca distintos relatos emblemáticos de su narrativa, se analiza cómo el autor propone ontologías literarias que formula apelando a la construcción de una base epistemológica que reúne conceptos propios de la práctica de la hipnosis (que recupera de sus textos de divulgación científica) o pertenecientes a la parapsicología y la mecánica cuántica. En este sentido, la propuesta final de Carneiro parece orientada a construir, bajo la influencia de un sincretismo epistemológico que reúne los mencionados paradigmas, un modelo de realismo singular.

Palabras clave: André Carneiro, ciencia ficción, límites de la literatura, autonomía literaria, hipnosis, parapsicología, mecánica cuántica, realismo. 